Rev Inv Vet Perú 2013; 24(4): 551-554

\title{
Comunicación
}

\section{PSEUDOHERMAFRODITISMO CANINO: DESCRIPCIÓN DE UN CASO}

\author{
Canine Pseudohermaphroditism: A Case Description
}

Alfonso Sánchez R., ${ }^{1,3}$, Luis Raiteri R. ${ }^{2}$

\section{Resumen}

Se describe el caso de un perro mestizo de ocho meses con evidencias de alteraciones en la diferenciación sexual. Se observó desarrollo incompleto del prepucio, micropene sin presencia de abertura uretral, escroto bífido y pseudovagina con presencia de abertura uretral. Se discuten los hallazgos y se postula un posible síndrome de feminización testicular con resultado de pseudohermafroditismo masculino.

Palabras clave: diferenciación sexual, pseudohermafroditismo, perro

\section{Abstract}

The case of an 8 month-old crossbred dog with evidences of impaired sexual differentiation is described. There was an incomplete foreskin development, micropenis without urethral opening, bifid scrotum, and pseudovagina with urethral opening. The findings are discussed and a possible testicular feminization syndrome is assumed that resulted in a male pseudohermaphroditism.

Key words: sexual differentiation, pseudohermaphroditism, dog

\footnotetext{
${ }^{1}$ Escuela de Medicina Veterinaria, Universidad Santo Tomás, Viña del Mar, Chile

${ }^{2}$ Clínica Veterinaria Centenario, Los Andes, Chile

${ }^{3}$ E-mail:profesanchez@gmail.com
}

Recibido: 13 de abril de 2013

Aceptado para publicación: 24 de junio de 2013 
INTRODUCCIÓN

Las diferencias sexuales en los mamíferos son expresadas en varios niveles del desarrollo de los individuos; esto es, el establecimiento del sexo cromosómico, el desarrollo del sexo gonadal, el desarrollo del sexo fenotípico y, en etapas más avanzadas, la expresión del sexo conductual. El sexo del individuo queda determinado en el momento de la fecundación, estado en que se denomina sexo genético o cromosómico. En condiciones normales, el sexo es masculino (XY) o femenino (XX). Asimismo, durante el desarrollo temprano del embrión pasa un tiempo sin que existan diferencias morfológicas entre embriones de un sexo u otro, y este lapso se conoce como periodo indiferenciado del desarrollo sexual (Rey, 2001).

La determinación de sexo gonadal es el proceso por el cual se induce a la gónada indiferenciada a que se convierta en testículo u ovario. A partir de la expresión del gen SRY en los fetos XY, las futuras gónadas inician una serie de eventos caracterizados por expresión de proteínas que determinan cambios citológicos, histológicos y funcionales característicos de los testículos. El proceso de diferenciación de los genitales se denomina diferenciación sexual (Meyers-Wallen, 2001).

La diferenciación de conductos internos, órganos sexuales accesorios y genitales externos en el feto ocurre en respuesta a la presencia o ausencia de hormonas testiculares: la testosterona $\left(\mathrm{T}_{2}\right)$ producida por las células de Leydig y la hormona anti-Mülleriana (AMH) producida por las células de Sertoli. Los conductos paramesonéfricos o de Müller se atrofian en respuesta a la AMH. Asimismo, la $\mathrm{T}_{2}$ es directamente responsable de la masculinización y desarrollo de los conductos mesonéfricos o de Wolff. Por la acción de la $5 \alpha$-reductasa, la $\mathrm{T}_{2}$ se convierte en dihidrotestosterona (DHT), masculinizando dichas estructuras. Tanto la $\mathrm{T}_{2}$ como la DHT ejercen sus efectos a través de receptores de andrógenos (AR) (Morrish y Sinclair, 2002).
Fallas en el establecimiento del sexo cromosómico, gonadal o fenotípico causan anormalidades en la diferenciación sexual y los individuos afectados pueden ser identificados por una amplia variedad de patrones, desde genitales ambiguos hasta genitales aparentemente normales pero con problemas de infertilidad o esterilidad (Lyle, 2007).

\section{Caso Clínico}

Se presenta a consulta (Clínica Veterinaria Centenario, Los Andes, Región de Valparaíso, Chile) un canino macho, mestizo, peso corporal de $12.5 \mathrm{~kg}$, con una edad estimada en 8 meses y con evidencia de anomalías en el aparato reproductor externo.

A la inspección se observó desarrollo incompleto de la región ventral del prepucio con exposición de un micropene, destacando la ausencia del bulbo del glande y del orificio uretral externo (Fig. 1). Los testículos estaban ubicados en bolsas escrotales independientes, separadas por un rafe escrotal muy marcado generando un escroto bífido (Fig. 2a) que se extiende desde la base del pene hacia posterior para unirse con una cavidad muy corta que asemeja una vagina, inmediatamente por debajo del ano (Fig. 2b). Asimismo, se pudo constatar que el orificio uretral externo se encontraba en la pseudovagina.

A la palpación, los testículos presentaban un tamaño y consistencia normal, los epidídimos estaban completos aunque de tamaño levemente reducido.

\section{Discusión}

En el presente caso, si bien no fue posible realizar un estudio del sexo genético, se asume que se trata de un individuo XY dada la presencia de testículos, epidídimos y genitales externos masculinos. El grupo de defectos fenotípicos observados en los 


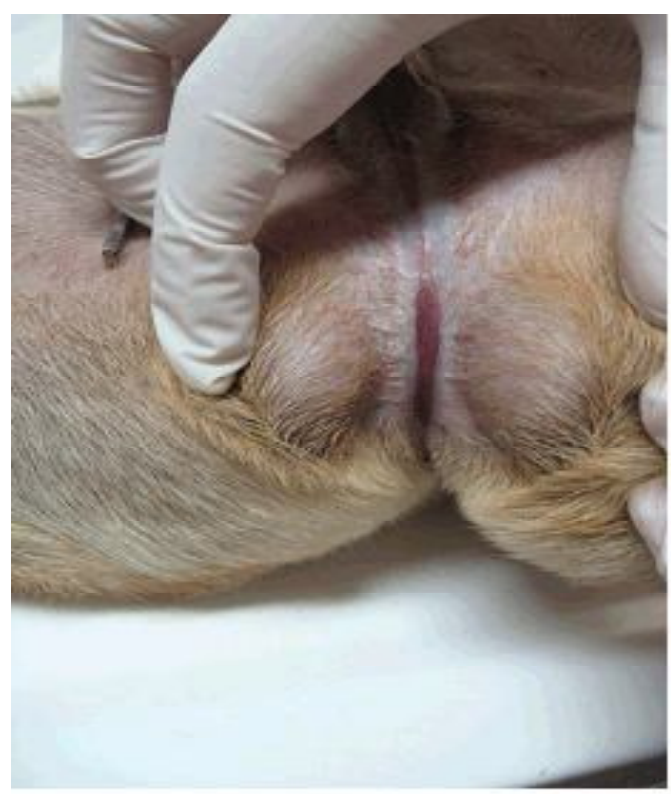

(a)

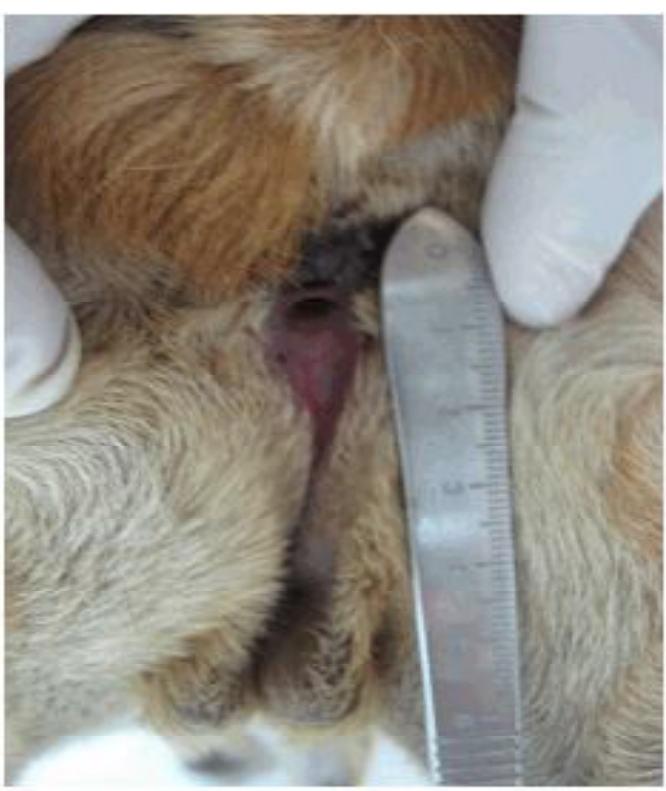

(b)

Figura 2. Pseudohermafroditismo canino. a) Testículos ubicados en bolsas escrotales independientes y separadas por un rafe medio (escroto bífido). b) Pseudovagina por debajo del ano, que se continúa con el rafe que separa los testículos
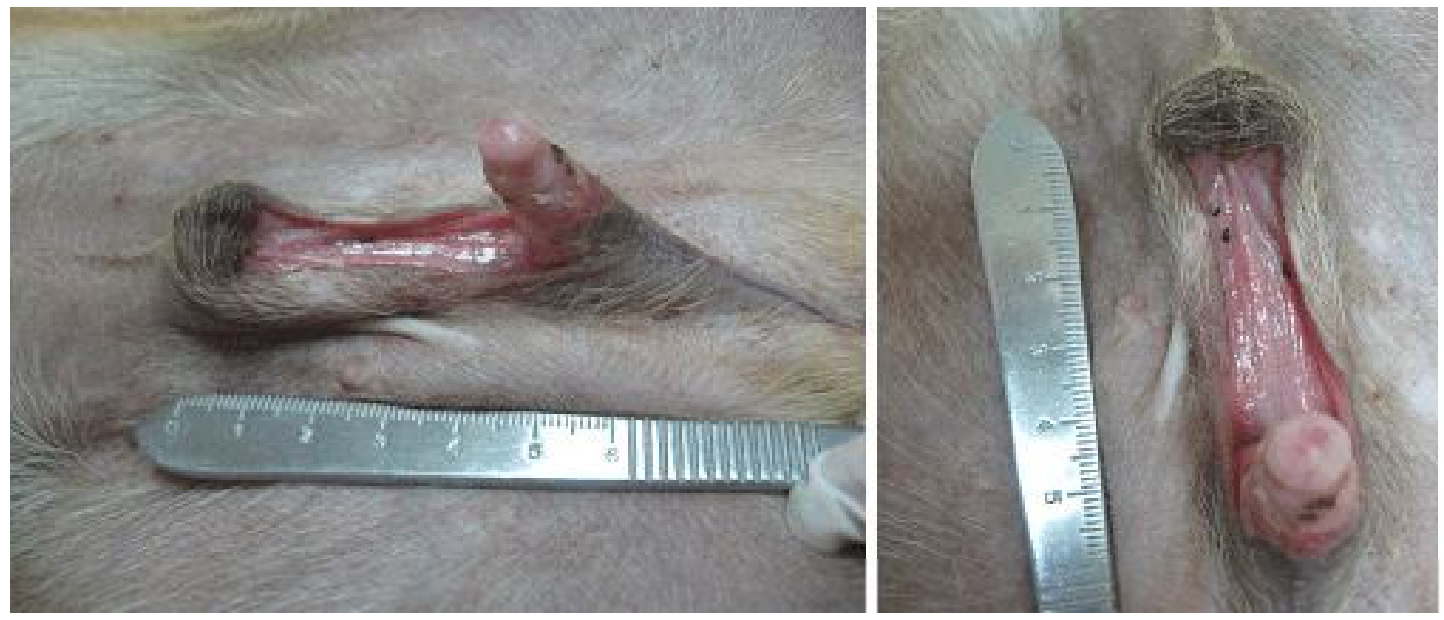

Figura 1. Desarrollo incompleto de la región ventral del prepucio, con exposición de un micropene sin orificio uretral externo

genitales externos, tales como micropene, escroto bífido, desarrollo incompleto de prepucio y pseudovagina permiten indicar que se trata de una alteración de la diferenciación sexual.
En el desarrollo normal, durante el proceso de diferenciación sexual, los genitales externos del feto XY dependen de tres factores: producción de $\mathrm{T}_{2}$ testicular, conversión de $\mathrm{T}_{2}$ a DHT por la enzima $5 \alpha$-reductasa y 
presencia de receptores androgénicos en los tejidos andrógeno dependientes (MeyersWallen, 2001). Así por ejemplo, el tubérculo genital origina el pene, en tanto que los pliegues labioescrotales se agrandan y se fusionan en sentido póstero-anterior para formar las bolsas escrotales. La punta del falo está cubierta por un cordón epitelial corto que penetra en la uretra para encontrar el revestimiento uretral y que posteriormente se canaliza formando el meato uretral en la punta del glande y al canalizarse en la periferia forma el prepucio (Rey, 2001).

Las alteraciones fenotípicas observadas en el presente caso permitirían definirlo como un pseudohermafroditismo masculino, el que podría estar asociado a un síndrome de feminización testicular (SFT), patología que resulta de mutaciones cualitativas o cuantitativas en el gen del receptor de andrógenos ligado al cromosoma $X$, generando una resistencia a los andrógenos, con un amplio espectro de fenotipos que corresponden a diversos grados de masculinización insuficiente, determinado por grados de alteración funcional de los receptores androgénicos (Lyle, 2007). La literatura especializada menciona el caso de un gato de raza Himalaya, XY, con escroto bífido, hipoplasia de las espículas peneanas y protrusión de una estructura similar a una vulva, que fue definido como pseudohermafrodita masculino (Bredal et al., 1997).

\section{Literatura Citada}

1. Bredal W, Thoresen S, Kvellestad A, Lindblad K. 1997. Male pseudohermaphroditism in a cat. J Small Anim Pract 38: 21-24.

2. Lyle S. 2007. Disorders of sexual development in the dog and cat. Theriogenology 68: 338-343.

3. Meyers-Wallen V. 2001. Inherited abnormalities of sexual development in dogs and cats. In: Concannon P, England G, Verstegen J (eds). Recent advances in small animal reproduction. Ithaca, New York: International Veterinary Service (www.ivis.org).

4. Morrish B, Sinclair A. 2002. Vertebrate sex determination: many means to an end. Reproduction 124: 447-457.

5. Rey R. 2001. Diferenciación sexual embrio-fetal: De las moléculas a la anatomía. Rev Chil Anat 19(1): 75-82. 